Beograd

\title{
GLAGOL hteti I STRUKTURA POMOĆNIH I MODALNIH GLAGOLA U SRPSKOHRVATSKOM JEZIKU
}

U gramatikama srpskohrvatskog jezika glagol hteti se obično klasifikuje kao pomoćni glagol, mada se pri tome ističe da se buduće vreme gradi od enkliktičkih oblika glagola hteti i infinitiva glagola koji se menja (Stevanovic, 1983: 350). Ovakvo shvatanje predstavlja znatnu teškoću u izgradnji jedne generativne gramatike srpskohrvatskog jezika, jer ono zahteva da se enkliktički oblici u sinhronoj jezičkoj ravni izvode iz punih oblika glagola hteti što nije uvek moguće. U ovom prilogu mi želimo da ukažemo na razloge zbog kojih se u sinhronoj gramatici sroskohrvatskog jezika glagol hteti ne može shvatiti kao romoćni glagol niti se enkliktički oblici ću, ćeš, će... mogu izvoditi iz punih oblika glagola hteti. Nakon iscrpne diskusije o distribuciji glagola hteti i biti u drugom delu članka se odredjuje odnos pomoćnih i modalnih glagola pomoću pravila rečeničke strukture. Takodje se pokazuje da je u okviru generativne gramatike moguća i alternativna analiza svih glagola kao glavnih u smislu Rossovog članka iz 1969. god. U tom slučaju se poredak pomoćnih i modalnih glagola u površinskoj strukturi mora osigurati pomoću odgovarajúeg filtra.

1. Podvršćavanje glagola hteti i oblika ću, ćeš, će...

Glagol hteti: i oblici ću, ćeš, će... se samo delimično slažu u pogledu dopuna koje dopuštaju. Oba glagolska oblika mogu da imaju infinitivne dopune.

(1) a. Milan hoće ići u Pariz.

b. Milan će ići u Pariz.

Dalje, ovi glagolski oblici dopuštaju kao dopune i rečenice s identičnim subjektom.

(2) a. Milan hoce da ide u Pariz.

b. Milan ce da ide u Pariz. 
Medjutim, glagol hteti dopušta kao dopune i rečenice drugačije strukture.

(3) a. Ja hoću da oni dodju.

b. *Ja cu da oni dodju.

Pored toga, glagol htetidopušta imeničku dopunu.

(4) a. Ja hoću jabuku.

b.?Ja Eu jabuku.

Dok je rečenica (4a) potpuna i znači otprilike isto što i Ja želim jabuku, 'l rečenica (4b) je nepotpuna - njeno značenje zavisi od konteksta. Rečenica (4b) može, na pr. da znači Ja ću jesti jabuku, ali može da znači i ja ću seći jabuku. Prema tome, glagol hteti treba u leksikonu podvrstiti na četiri načina:

$$
\text { hteti }\left\{\begin{array}{l}
\text { infinitiv } \\
\text { da }+ \text { prezent } \\
\text { imenička fraza } \\
\text { rečenica }
\end{array}\right\}
$$

S druge strane, oblici ću, ćeś, će... se podvršćaju na dva načina infinitiv da + prezent

Sada treba ispitati da li se ovo podvršćavanje može uprostiti time što bi se neke dopune svele na preostale dopune u (5) i (6). Tako na pr. Wayles Browne (1974) je dokazivao da se dopuna $d a+$ prezent može izvesti iz rečeničke dopune. U daljem izlaganju ja ću pokazati da to shvatanje nije opravdano.

2. Status dopune $d a+$ prezent

Radi ispitivanja podvršćavanja (5) i (6) možemo primeniti više testova. Prvo, možemo primeniti test pripisivanja dva priloška dođatka za vreme pretpostavljajući da su oni saglasni jedino s onim podvršćavanjima koja proističu iz rečeničke dopune. Možemo primetiti da rečenice sa $d a+$ prezent kao i rečenice sa infinitivom nisu sasvim prihvatljive sa dva priloška dodatka.

(7) a.?Ja hoću danas da sutra idem u bioskop. b. *Ja cu danas da sutra idem u bioskop. 
(8) a.*Ja hocu danas ići sutra u bioskop.

b. *Ja ću danas ići sutra u bioskop.

Neprihvatljivost rečenica (7) pokazuje da se dopuna da + prezent ne može izjednačiti s rečeničkom dopunom. Rečenice (8) pokazuju da isto ograničenje važi i za infinitivnu dopunu. To se još više oseća ako je glagol hteti u aoristu.

(9) a.*On baš sada htede da vas poseti iduće nedelje. b.*On baš sada htede posetiti vas iduće nedelje.

Prema tome, dopuna da t prezent se ne može izjednačiti s rečenicom ni za glagol hteti niti za oblike ću, češ, će...

Drugi argument se tiče reda reči: u prostoj srpskohrvatskoj rečenici red reči je relativno slobodan. I zaista, rečenice (10) i (11) znače isto.

(10) Ja $\left\{\begin{array}{l}\text { hoću } \\ \text { cu }\end{array}\right\}$ danas da idem u bioskon.

(11) Ja $\left\{\begin{array}{l}\text { hoću } \\ c ́ u\end{array}\right\}$ da idem danas u bioskop.

U složenim rečenicama, medjutim, mesto priloškog dodatka nije slobodno. Rečenice (12) ne znače isto.

(12) a. On je juče kazao da odeš na poštu. b. On je kazao da juče odeš na poštu:

Najzad, navedimo jedan test specifičan za srpskohrvatski jezik. K - pitanja u srpskohrvatskom su, izgleda, ograničena na glavne rečenice u slučaju kada je $\mathrm{K}$ - fraza objekat u rečenici. Tako na pr. rečenica ??Koga Milan kaže da Milena voli? nije potpuno ispravna. S druge strane, rečenice

(13) a. Koga hoće Milan da poseti?

b. Koga hoće Milan posetiti?

su potpuno korektne.

Prema tome, sva tri navedena testa govore u prilog pretpostavke da da + prezent nije rečenička dopuna. Isto tako, ovi testovi pokazuju paralelizam izmedju dopune $d a+$ prezent i infi-: nitivne dopune. Sada Cemo pokazati da ovi isti testovi daju suprotne rezultate u slučaju rečeničke dopune glagola hteti. 
Prvo, takve rečenice dopuštaju dve priloške odredbe. Rečenice (14) izgledaju prihvatljive.

(14) a. On hocé danas da oni sutra dodju.

b. On je juče hteo da oni sutra dodju.

Drugo, položaj priloške odredbe nije slobodan. Rečenice (15) ne znače isto.

(15) a: On je juče hteo da oni dodju.

b. On je hteo da onì dodju juče.

Treče, K-pitanja pomenute vrste nisu s takvim rečenicama potpuno ispravna.

(16) ??Koga hoće Milan da Milena prevari?

Prema tome, ovi testovi pokazuju da se infinitivna $i$ prezentska dopuna jasno razlikuju od rečeničke dopune i da se ne mogu svesti na nju. Paralelizam izmedju infinitivne $i$ prezentske dopune, naprotiv, pokazuje da se ove dopune, u principu, mogu izvoditi jedna iz druge.

Izvodjenje imeničke dopune iz rečeničke dopune koje je McCawley (1973) predlagao za engleski glagol want ne izgleda moguće u slučaju srpskohrvatskog glagola hteti. Test sa povratnom zamenicom nedvosmisleno daje negativan rezultat.

(17) Milan hoće svoja kola.

U (17) je zamenica svoja koreferentna s Milan potvrajujući intuiciju da je (17) prosta rečenica. (Refleksivne zamenice su, po pravilu, koreferentne s antecedentom u istoj prostoj rečenici.) Prema tome, nema nikakvog razloga da se imenička dopuna izvodi iz rečeničke. Sem toga, takvo izvodjenje bi zahtevalo potpuno proizvoljna brisanja. (Kao kad se na pr. (17) izvodi iz Milan hoće da vozi svoja kola... $)^{2}$

3. Sprezanje infinitiva

U prethodnom odeljku smo pokazali da su podvršćavanja (5) i (6) bila ispravna. Sem toga smo utvrdili paralelizam infinitivne dopune $i$ dopune $d a+$ prezent. Taj paralelizam opravdava uvodjenje sledeće transformacije: 
(18)

$$
\begin{aligned}
& V \text { hteti G } \\
& \text { I } 2 \quad 3 \longrightarrow 1 \\
& {\left[\begin{array}{lll}
\alpha & b r o j \\
\beta & l i c e
\end{array}\right]}
\end{aligned}
$$

Transformacija (18) je fakultativna. Ona prepisuje lice i broj s glagola hteti na "glavni" glagol i umeće veznik da i oznaku "prezent". U (18) se pretpostavlja da hteti može da ima bilo pun bilo skraćeni oblik. Na osnovu (18) moguće je pojednostaviti podvršćavanja glagola hteti i oblika ću, ćeš, će... Sada je dovoljno glagol hteti podvrstiti na tri načina:

$$
\text { hteti }\left\{\begin{array}{l}
\text { infinitiv } \\
\text { imenička fraza } \\
\text { rečenica }
\end{array}\right\}
$$

oblïci ću, ćeš, će... se sada mogu podvrstiti samo sa infinitiv

Transformacija (18) doprinosi na taj način pojednostavljenju leksikona. Ona, naravno, mora da sledi operaciju slaganja. Pored toga, transformacija (18) čini izlišnom operaciju brisanja iste imeničke fraze (Equi IF brisanje). S obzirom da operacija Equi IF brisanja zahteva raziličita ad hoc ograničenja (Brame, 1976:100), gramatika koja tu operaciju čini izlišnom se mora predpostaviti iz razloga jednostavnosti. ${ }^{3}$ Razmotrimo sledeće rečenice:

(21) a. Milan hoće da ide u bioskop.

b. Milan hoće da on ide u bioskop.

Rečenica (2la) se može izvesti preko transformacije (18), a (21b) ne može. Medjutim, u rečenici (2lb) Milan i on su koreferentni jedino ako na on pada rečenički naglasak, ali u tom slučaju se i ne pretenduje na to da on i Milan pripadaju istoj rečenici. (2lb) se, dakle, izvodi iz strukture Milan hoće $\mathbb{R}^{[d a}$ on ide u bioskop] $]_{R}$ u kojoj se zamenici on prema jednom obaveznom pravilu $i l i$ transformaciji pripisuje rečenički naglasak ako je to on koreferentno sa milan. Na taj način se bez ikakvih 
dodatnih ograničenja sprečava generisanje negramatičkih rečenica. Treba primetiti da se (18) primenjuje samo na glagol hteti koji je praćen infinitivom. Usled toga se moraju razlikovati dva glagola hteti, hteti ${ }_{1} i$ hteti $_{2}$ koji se podvršćuju na sledeći način:

$$
\text { hteti }_{1} \begin{aligned}
& \text { infinitiv } \\
& \text { hteti }
\end{aligned} \quad\left\{\begin{array}{l}
\text { imenička fraza } \\
\text { rečenica }
\end{array}\right\}
$$

Glagol hteti, se uvodi preko pravila rečeničke strukture, a glagol hteti ${ }_{2}$ preko leksičkog umetanja u oznaku G - glagol. Rečenica (2lb) sadrži, prema tome, glagol hteti ${ }_{2}$.

4. Razlike u distribuciji

Na osnovu (20) i (22) bị se sada moglo tvrditi da se skraćeni oblici ću, ćeš, će... mogu izvesti iz glagola hteti jer imaju istu dopunu. Da je takvo tvrdjenje neodrživo pokazuju sledeći primeri :

(24) a. On će sutra hteti da ide u bioskop. b.*On hoće sutra hiteti da ide u bioskop.

Rečenice (24) pokazuju da sve okoline enkliktičkih oblika ću, ćeś, će ... nisu istovremeno i okoline glagola hteti. Naime, infinitivna dopuna enkliktičkih oblika ću, ćeš, će ... može da bude $i$ glagol hteti, dok glagol hteti ne može da bude sam sebi infinitivna dopuna. Usled toga se enkliktički oblici ću, ćeš, će ... ne mogu bez natezanja izvoditi iz punih oblika glagola hteti.

Treba primetiti da postoji još jedna razlika u distribuciji oblika ću, ćeš, će ... i glagola hteti. Glagol hteti se može u obliku participa javiti kao dopuna glagola biti, dok je analogno pojavljivanje oblika ću, ćeš, će... naravno isključeno.

(25) a. On je juče hteo da idè u bioskop.

b. On bi hteo da ide sutra u bioskop.

c. On bejaše hteo da ide u bioskop.

Rečenice (25) pokazuju da se oblici ću, ćeš, će ... i glagol hteti moraju razlikovati i s obzirom na odnos prema glagolu biti: jedino glagol hteti se može javiti iza glagola biti. ova 
relacija je važna za utvrdjivanje poretka pomoćnih i modalnih glagola u srpskohrvatskom jeziku.

5. Modalni glagoli

Modalni glagoli morati, moći, smeti, umeti imaju neka osnovna svojstva istovetna s glagolom hteti. Slično kao i glagol hteti modalni glagoli dopuštaja $i$ infinitivnu $i$ prezentsku dopunu.

$$
\begin{gathered}
\text { (26) a. Milan }\left\{\begin{array}{c}
\text { može } \\
\text { mora } \\
\text { sme } \\
\text { ume }
\end{array}\right\} \text { da ide sam u bioskop. } \\
\text { b. Milan }\left\{\begin{array}{l}
\text { može } \\
\text { mora } \\
\text { sme } \\
\text { ume }
\end{array}\right\} \text { ići sam u bioskop. }
\end{gathered}
$$

Odgovarajuće rečenice (26) su ekvivalentne kao i rečenice sa glagolom hteti. Ovo ukazuje na srodnost modalnih glagola s glagolom hteti. Doduše, modalni glagoli ne dopuštaju imeničku ili rečeničku dopunu. Rečenice (27) nisu ispravne.

$$
\begin{gathered}
\text { (27) a.*Ja }\left\{\begin{array}{l}
\text { mogu } \\
\text { moram } \\
\text { smem } \\
\text { umem }
\end{array}\right\} \text { jabuku. } \\
\text { b. *Ja }\left\{\begin{array}{l}
\text { mogu } \\
\text { moram } \\
\text { smem } \\
\text { umem }
\end{array}\right\} \text { da oni dodju. }
\end{gathered}
$$

Rečenice (27) se ne mogu prihvatiti kao potpune, korektne rečenice. To pokazuje da su modalni glagoli podvršćeni u leksikonu na isti način kao hteti, sa __ infinitiv. Kao i glagol hte$t i$, modalni glagoli podležu operaciji Sprezanja infinitiva. Štaviše, modalni glagoli se slobodno javljaju u rečenicama tipa (24a) i (25).

(28) Milan će sutra $\left\{\begin{array}{l}\text { moći } \\ \text { morati } \\ \text { smeti } \\ \text { umeti }\end{array}\right\}$ da ide u bioskop. 
(29) Milan $\left\{\begin{array}{c}j e \\ b i\end{array}\right\} \quad\left\{\begin{array}{c}\text { mogao } \\ \text { morao } \\ \text { smeo } \\ \text { umeo }\end{array}\right\}$ da ide u bioskop.

Prema tome, modalni glagoli i glagol hteti ${ }_{1}$ imaju potpuno istu distribuciju. ${ }^{4}$. To, u stvari, znači da je hteti, modalan glagol. $\mathrm{Na}$ taj način se objašnjava zašto rečenice

(30) a. Milan hoce kupiti auto. (prezent)

b. Milan hočaše kupiti auto. (imperfekt)

c. Milan htede kupiti auto. (aorist)

ne sadrže nikakva složena vremena. U srpskohrvatskom jeziku su jedino glagol biti i enkliktički oblici ću, ćeš, će ... pomoćni glagoli koju učestvuju u gradnji složenih vremena. Glagol hte$t i_{2}$ je "glavni" glagol u odgovarajućim rečenicama. Razmotrimo sada ukratko različite upotrebe glagola biti.

6. Glagol biti

Glagol biti se obično upotrebljava u rečenicama sledećeg tipa:

(31) a. Beograd je glavni grad Jugoslavije.

b. Ti bejaše umoran.

c. Marko je kod kuće.

d. Ona je čitala knjigu.

U prve tri rečenice (3I) biti je glavni glagol, a u poslednjoj pomoćni. Pomoćni glagol biti možemo označiti sa biti, a glavni glagol biti sa biti ${ }_{2}$. Ti glagoli se podvršćuju na sledeEi način:

$$
\text { biti }_{2}\left\{\begin{array}{r}
\text { radni pridev } \\
\text { imenička fraza } \\
\text { pridevska fraza } \\
\text { predloška fraza }
\end{array}\right\}
$$

$B_{i t i_{2}}$ se umeće u oznaku G - glagol, a biti, se uvodi preko pravila rečeničke strukture.

7. Struktura pomoenih $i$ modalnih glagola u srpskohrvatskom jeziku 
U prethodnim odeljcima smo pokazali da je hteti, modalan, a biti, pomoćni glagol. Rečenice (28) i (29) pokazuju da se modalni glagoli moraju uvesti posle pomoćnog glagola biti i posle enkliktičkih oblika ću, ćeš, će ... Pošto se enkliktički oblici ću, ceš, ce ... poglavito upotrebljavaju za gradnju futura mi cemo ih označiti sa "f. morfeme". (futur morfeme). Poredak pomoknih i modalnih glagola se tada može jednostavno predstaviti pomoću sledećih pravila rečeničke strukture:

$$
\begin{aligned}
& \text { a. } R \rightarrow-\rightarrow \text { IF Aux GF } \\
& \text { b. Aux } \longrightarrow \rightarrow\left\{\begin{array}{cc}
V & \text { (biti) } \\
\text { f. morfem }
\end{array}\right\} \text { (Modal) } \\
& \text { c. } \mathrm{v} \longrightarrow\left\{\begin{array}{l}
\text { prezent } \\
\text { aorist } \\
\text { imperfekt }
\end{array}\right\} \\
& \text { d. Modal } \rightarrow\left\{\begin{array}{l}
\text { hteti } \\
\text { moći } \\
\text { morati } \\
\text { umeti } \\
\text { smeti }
\end{array}\right\}^{5)}
\end{aligned}
$$

gde $R, I F, G F, V$ označavaju redom rečenicu, imeničku frazu, glagolsku frazu i glagolsko vreme, a "f. morfem" oblike ću, ćes, će ... Prema (34), pomoćnim glagolima, kad god su prisutni, pripada odredjeno vreme. Ova osnovna osobina pomoćnih glagola je u stvari posledica utvrdjenog reda pomoćnih i modalnih glagola u $(34$ b). Neki lingivisti, medjutim, osporavaju postojanje čvora Aux jer se taj čvor ne javlja kao konstituent ni u jednoj transformaciji (cf. Huddleston (1976), Pullum i Wilson (1977)). Prema tom shvatanju jedina funkcija čvora Aux je da fiksira poredak pomoćnih $i$ modalnih glagola $u$ površinskoj strukturi.

Primetimo da se može pokazati da čvor Modal nije izlišan u srpskohrvatskom jeziku. Razmotrimo ponovo transformaciju sprezanje infinitiva. Sada smo u mogućnosti da na osnovu $\$ 5$ i pravila (34) damo toj transformaciji opštiji oblik. Sprezanje infinitiva mora da sledi transformaciju slaganja koja kopira rod, broj i lice na segment koji sledi $v$ oznaku. 
sprezanje infinitiva

(35)

$$
\begin{array}{ccc}
x & \begin{array}{c}
\text { (Modal) } \\
1
\end{array} \quad 2 & 3 \\
{\left[\begin{array}{ll}
\alpha \text { broj } \\
\beta & 1 \text { ice }
\end{array}\right]} & \rightarrow 1
\end{array}
$$

Uslov: Ako je $2=\varnothing$, onda je $x=f$. morfem

Sprezanje infinitiva se ne primenjuje na modalne glagole, jer bi nastala negramatička rečenica tMarko će da mora ići u školu. Transformacija (35) predvidja da se samo glagol i.za modalnog glagola ili futur morfema spreže. Oznaka "Modal" je neophodna u opisu transformacije (35), a to predstavlja novu evidenciju u prilog naše analize jer pokazuje da čvor "Modal" nije izlišan.

8. Pomoćni glagoli kao glavni

U okviru transformacione generativne gramatike moguća je i alternativna analiza prema kojoj se svi glagoli tumače kao glavni kao što je predložio Ross još 1969 god. Peterson (1974) i Pullum i Wilson (1977) su uspešno dokazivali da takva analiza ima za engleski jezik značajne prednosti. Izvesne činjenice ukazuju da je takva analiza pogodna i za srpskohrvatski jezik. Tako na pr. u rečenicama

(36) a. Milan je morao ici u bioskop, a Milena ne. b. Milan je morao ići u bioskop, a Milena nije (morala).

i modalni i.glavni glagol mogu biti izbrisani (cf. Kalogjera, 1982: 21). Zato je pogodno rečenici milan je morao ići u bioskop dati sledeću strukturu:

(37)

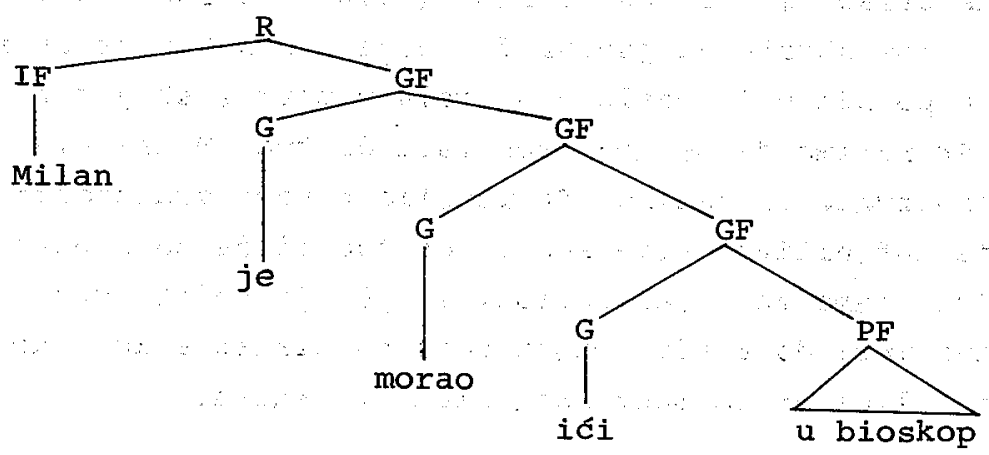


Ovakva struktura omogucava da se transformacija GF brisanje definiše preko konstitutivnih elemenata.

GF brisanje 6

GF

USlov: $1=3$.

slično tome, transformacija inverzije subjekta i susednog glagolskog oblika se može jednostavno $i$ pogodno formulisati u novoj analizi (cf. Peterson (1974, 9) i Pullum i wilson (1977: 781).

Ako se svi glagoli shvate kao glavni, pravila rečeničke strukture (34) se morajú zameniti sa (39).

$\begin{aligned}(39) & \text { a. } \mathrm{R} \longrightarrow \mathrm{IF} \mathrm{GF} \\ & \text { b. GF } \longrightarrow \mathrm{G}\left\{\begin{array}{ll}\mathrm{GF} & \\ (\mathrm{IF}) & (\mathrm{PP})\end{array}\right\}\end{aligned}$

Da bi se obezbedio pravilan poredak pomocnih $i$ modalnih glagola u površinskoj strukturi, pravila (39) se moraju dopuniti filtrom koji bi sve "nepravilne" nizove markirao kao negramatičke. Taj filtar mora da ima sledeći oblik:

$$
\text { (40) }\left\{\begin{array}{c}
b^{\text {tti }_{1}} \\
\text { f.morfem }
\end{array}\right\} \text { (Modal) G }
$$

Filtar (40) ostvaruje istu funkciju koju u prethodnom modelu vrše pravila rečeničke strukture (34). Usled ovoga se može ste$\epsilon_{i}$ utisak da nova analiza predstavlja samo notacionu varijantu prethodne. Sem toga, filtar (40) se u srpskohrvatskom jeziku ne može nezavisno motivisati kako su to za analogni filter u engleskom dokazivali Pullman $i$ Wilson (1977: 775): Kao neosporna prednost nove analize ostaje činjenica da ona omogućava jednostavne definicije nekih osnovnih transformacija u skladu s ograničenjem da se samo konstituenti mogu pomerati ili brisati.

Primetimo najzad da je za formulisanje operacije sprezanja infinitiva $i$ u novoj analizi neophodna kategorija modalnih glagola. Rečenica (4lb) je negramatička zbog toga što je transformacija infinitiva pogrešno primenjena na modalne glagole. 
(41)

a. Milan ce da ide u bioskop.

b. *Milan će da mora da ide u bioskop.

Transformacija sprezanje infinitiva se mora selektivno primenjivati na glagole u zavisnosti od toga da li nose odliku [+modal] ili [-modal]. Prema tome, kategorija modalnosti se u izmenjenom obliku čuva $i$ u analizi koja sve glagole tretira kao glavne. Ta analiza pojednostavljuje formulaciju nekih osnovnih transformacija, ali zahteva uvodjenje filtra. Treba primetiti da preko filtra naši rezultati o poretku pomoćnịh i modalnih glagola ostaju na snazi i u analizi koja sve glagole tretira kao glavne. Potpunija ocena te analize zavisi, medjutim, od daljeg proučavanja procesa dopunjavanja u srpskohrvatskom jeziku.

9. Sažetak

Mi smo ispitali različite okoline u kojima se javljaju enkliktički oblici ću, ćeš, će... i oblici glagola hteti i utvrdili da se oni ne mogu svoditi jedni na drugo. To znači da hteti uopšte nije pomoćni glagol tj. ne učestvuje u gradnji složenih vremena srpskohrvatskog jezika. Prema njihovim dopunama razlikovali smo dva glagola hteti - hteti ${ }_{1} i_{\text {htet }}{ }_{2}$ Hteti $_{1}$ je modalni glagol, a hteti, "glavni" glagol odgovarajućih rečenica. Glagol biti smo takodje podvrstili na dva načina, kao biti ${ }_{1} i_{\text {kao biti }}$. Pored toga smo utvrdili da se dopuna $d a$ + prezent znatno razlikuje od rečeničke dopune, a da je gotovo paralelna infinitivnoj dopuni. Ovaj paralelizam omogućava definiciju transformacije Sprezanje infinitiva koja čini izlišnom Equi IF brisanje koje je u standardnom modelu TG povezano s različitim ad hoc ograničenjima. Ova analiza je omogućila da strukturu pomoćnih i modalnih glagola u srpskohrvatskom jeziku predstavimo pomoću pravila rečeničke strukture (34). Najzad smo pokazali da je u okviru TG moguća i alternativna analiza koja sve glagole tretira kao glavne, ali je u tom slučaju neophodan filtar koji fiksira poredak pomoénih i modalnih glagola. Činjenica da je i u novom modelu neophodna kategorija modalnih glagola za transformaciju sprezanje infinitiva predstavija značajnu evidenciju u prilog naše analize. 
1 Može se primetiti da je u (4a) više istaknut voljni momenat, a u Ja želim jabuku enocionalni.

2 Generativni gramatičari su svojevremeno oštro kritikovani zbog postuliranja takvih nemotivisanih apstraktnih struktura (cf. Brame 1976: 3-69).

3 Da bi se Equi IF brisanje potpuno odstranilo potrebno je definisati jednu transformaciju sprezanja infinitiva $i$ u odnosu na objekt glavne rečenice radi izvodjenja rečenica tipa"Naučio me je da plivam". U takvim rečenicama se u istočnoj varijanti sh jezika infinitivu pretpostavlja glagol u ličnom glagolskom obliku (Ivić, 1972).

4 Kalogjera (1982) tvrdi da u srpskohrvatskom modalni glagoli mogu da prethode jedni druge. Medjutim, njegov primer "Moraš moći učiti"nije ubedljiv. Marginalnost te rečenice se vidi $\dot{i}$ iz toga što ne postoji njen upitni ni odrečni oblik. Rečenice tMoraš $1 i$ moći učiti $i$ *Ne moraš moći učiti nisu gramatički ispravne.

5 U nekim govorima se i glagol trebati pojavljuje u ličnom glagolskom obliku.

6 Pullum i Wilson (1977) su uočili da Rassova analiza zahteva posebna ograničenja da bi se sprečilo generisanje rečenica poput *Sam was being examined by a psyhiatrist, and Bill was being too. U sh se sličan problem ne pojavljuje.

\section{BIBLIOGRAFIJA}

BRAME, M. 1976. Conjectures and refutations in syntax and semantics. Amstexdam: North-Holland.

BROWNE, W. 1974. On the problem of enclictic placement in serboCroatian, u: Slavic transformational syntax, ed. by $R$. Brecht and C. Chvany. Ann Arbor: University of Michigen.

HUDDLESTON, R. 1976. An introduction to English transformational syntax. London: Longman.

IVIC, M. 1972. Problematika srpskohrvatskog infinitiva, zbornik za filologiju i lingvistiku $x V / 2$.

KALOGJERA, D. I982. The English modals and their equivalents in serbo-croatian, The Yugoslav serbo-Croatian English Contrastive Project, zagreb: Istitute of Linguistics.

MCCAWLEY, J. 1973. On identifying the remains of deceased clauses, $u$ : Readings in the theory of grammar ed. by $D$. Borstein. Cambridge, MA: Winthorp Publishers.

PETERSON, T. 1974. Auxiliaries. Language Sciences 30.

PULLUM, G. i D.Wilson. Autonomous syntax and the analysis of auxiliaries, Language 53/4. 
ROSS, J. 1969. Auxiliaries as main verbs, u: studies in philosophical linguistics, series I ed. by W. Todd. Evanson: Great Expectation press.

STEVANOVIC, M. 1983. Savremeni srpskohrvatski jezik I, Beograd: Naŭnna knjiga.

\section{Summary}

THE VERB HTETI AND THE STRUCTURE OF AUXILIARY

AND MODAL VERBS IN SERBO'CROATIAN.

The analysis of the distribution of enclitic forms ću, ćes, ce ... and the verb hteti shows that they cannot be naturally reduced to each other. This means that the verb hteti is not an auxiliary verb at all, i. e. it does not take part in compound tenses in serbo-Croatian. According to their complements we have distinguished two verbs hteti - hteti, and hteti, Hteti, is a modal verb, hteti, a main verb. Furthermore, we have shown that there is a parallelism between complements "da + prezent" and "sentence" which can be best accounted for by a transformation (18), which may be called in English Subjugation of Infinitive. This analysis has enabled us to present the structure of auxiliary and modal verbs by rewrite rules (34). Finally, we have shown that an alternative analysis in which all verbs are conceived as main verbs is quite feasible. In this new analysis our results are preserved in the form of an obligatory filter. 